УДК 902 (092) (571.65)

\title{
О ЖИЗНЕННОМ ПУТИ И НАУЧНОЙ ДЕЯТЕЛЬНОСТИ Т. С. ТЕИНА
}

\author{
Лебединцев А. И. \\ ФГБУН Северо-Восточный комплексный научно-исследовательский институт \\ им. Н. А. Шило ДВО РАН, г. Магадан \\ E-mail: lebedintsev@neisri.ru
}

\begin{abstract}
Представлены биографические данные и основные результаты научной деятельности сотрудника лаборатории истории, археологии и этнографии СВКНИИ, археолога Т. С. Теина. Им охарактеризованы основные этапы развития древней эскимосской культуры Северной Чукотки, дана реконструкция хозяйства и культуры, исследованы общественный строй, религиозные верования и обряды эскимосов. Материалы раскопок на о. Врангеля внесли значительный вклад в изучение палеоэскимосского периода. Т. С. Теином получены представительные и ценнейшие материалы с древнейшего поселения древних охотников на морского зверя. Он исследовал религию и шаманизм азиатских эскимосов, выполнил детальные описания эскимосских сезонных праздников.
\end{abstract}

Ключевые слова: история археологических исследований, древние эскимосские стоянки, Северная Чукотка, Т. С. Теин.

DOI: $10.34078 / 1814-0998-2021-3-105-115$

Теин Тасян Сергеевич, эскимос по происхождению [Теин Т. С. Личное дело] (фото 1), родился 1 января 1938 г. на Чукотке в Наукане, маленьком эскимосском селении на высоком обрывистом берегу Берингова моря. Оно располагалось у горловины Берингова пролива на трех возвышенностях, разделенных оврагами и горными речками. Это было удобное место для наблюдения миграций ластоногих в проливе. В зимнее время охотники добывали нерп и лахтаков. Весной и осенью охотились на гренладских китов. Летом объектами промысла были моржи и серые киты. На скалах в летнее время жители селения собирали множество яиц на птичьих базаpax. Жили эскимосы в модернизированных ярангах (Теин, 1994в). Строительным материалом для жилищ служили дерево, камни, дерн и китовые кости. Сверху жилище закрывалось покрышкой из расщепленных моржовых шкур (фото 2).

Отец (1890 г. рожд.) был морским охотником и носил имя Теин, которое Тасян взял себе как фамилию. Умер отец в 1962 г., похоронен в с. Пинакуль. Мать Накаюк - домохозяйка. В их семье было одиннадцать детей, но не все выжили. Старшие братья Тасяна - Никуоляк, Емрытагин, Емрыкайн, сестра Кован Мария (1936 г. рожд.). Никуоляк и Емрытагин стали морскими зверобоями, сестра работала санитаркой в районной

(С) Лебединцев А. И., 2021 больнице с. Лаврентия, а Емрыкайн - известный косторез, заслуженный художник РСФСР, удостоен звания лауреата Государственной премии им. И. Репина. Два двоюродных брата жили в пос. Лаврентия и Лорино. Они танцевали в ансамблях «Уэлен» и «Белый парус».

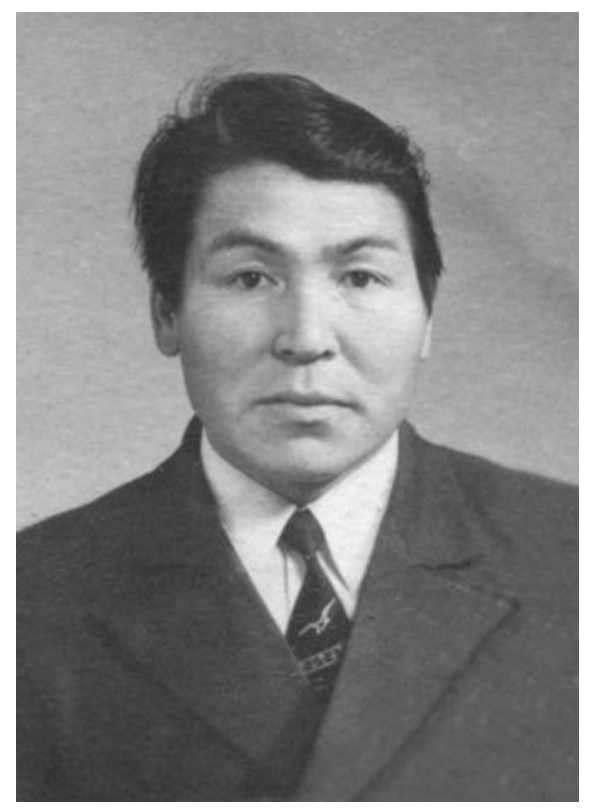

Фото 1. Тасян Сергеевич Теин в 1970-х гг. Photo 1. Tasyan S. Tein in the 1970 s 


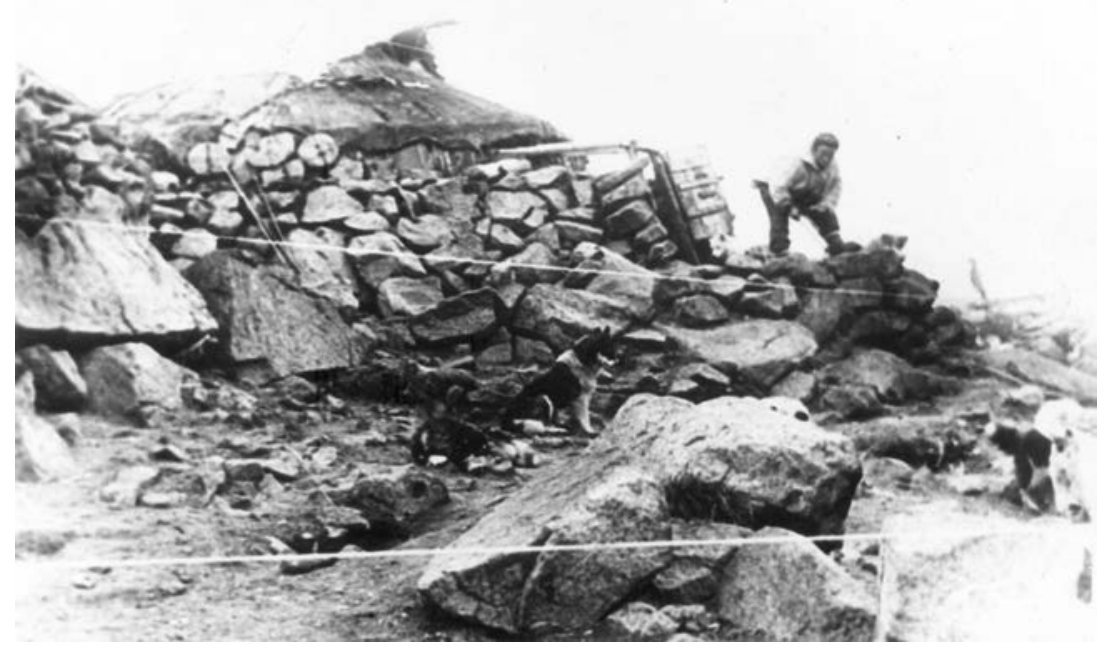

Фото 2. Жилище эскимосов в Наукане, 1948 г.

нужно дальше учиться, поступать в институт.

В 1965 г. Т. С. Теин поступил в Магаданский государственный педагогический институт, который закончил в 1969 г. по специальности учитель истории и обществоведения. Будучи студентом Магаданского пединститута, он, по просьбе областного управления культуры, занимался переводами с русского на эскимосский язык. Переводил пьесы, рассказы и сказки (Огрызко, 1990). Также он участвовал в организации чукотско-эскимосского ансамбля «Унпэнэр». В 1969 г. за активное участие в организации радиовещания на эскимосском языке, плодотворную

С ранних лет Тасян учился охотничьему искусству у своего отца и старшего брата. Взрослые брали его на охоту летом, а также зимой в свободное от учебы время. У него было свое детское снаряжение (два посоха - длинный и короткий, закидушка, вещевой мешок). Глубокое знание быта и культуры сородичей помогло ему впоследствии в исследовательской работе (Алехина, 1978).

T. С. Теин в детстве мечтал стать врачом. Окончив семь классов, он сначала работал в местном колхозе вместе с отцом на промысле морского зверя, а затем поступил на курсы радиотехников. В детстве и юности Тасяна интересовали секреты шаманских ритуалов. Он слушал рассказы стариков о том, как в прошлом проводились в Наукане праздники кита и как проходил первый спуск байдар на воду. В этих обрядах Тасян сумел увидеть беспредельную любовь эскимосов к природе, бережное отношение к ней, честность, мужество и отвагу своего северного народа (Денисов, 1977).

В 1958 г. окружное начальство решило, что Наукан, расположенный на скалах, неудобен для жизни, что имеются трудности в снабжении этого поселения продуктами и товарами морским транспортом, и его жителей расселили в другие поселки по всей Чукотке. Т. С. Теин с братьями перебрались в пос. Уэлен. Там Тасян устроился на работу в местный радиоузел (Огрызко, 2013).

В 1959 г. Т. С. Теин поступил в Анадырское педагогическое училище и после его окончания в 1964 г. был направлен в селение Нунямо учителем-воспитателем в интернат, где он вел уроки в подготовительном классе, в котором обучались чукотские и эскимосские дети. Когда он приезжал к матери, она всегда ему говорила, что

авторскую, переводческую и дикторскую работу T. С. Теин был награжден Почетной грамотой Магаданского комитета по радиовещанию и телевидению.

В 1969-1971 гг. Тасян Сергеевич работал учителем начальной школы на о. Врангеля (фото 3). В школе пос. Ушаковский он организовал школьный национальный ансамбль «Умкэкэй» («Белый медвежонок»). Дети с увлечением участвовали в небольших сценках из жизни чукчей и эскимосов. Для школьников Т. С. Теин сочинил песни «Славься, Советская Чукотка» и вальс «Воспоминание о маме». К 1 маю 1970 г. поставил спектакль «Солнце над тундрой», который понравил-

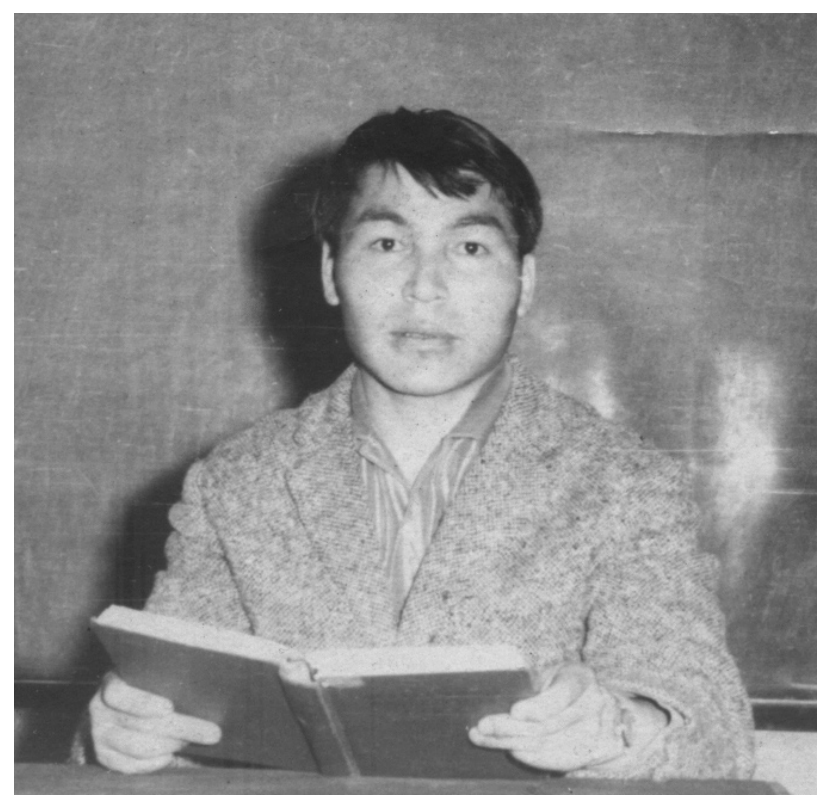

Фото 3. Т. С. Теин. Работа учителем на Чукотке Photo 3. T. S. Tein. Working as a teacher in Chukotka 
ся зрителям поселка. Кроме того, он подготовил историко-просветительскую постановку «Великий поворот» о событиях гражданской войны на Чукотке. Дети о. Врангеля любили спокойного и немного застенчивого учителя. Его учительская и просветительская деятельность была отмечена педагогическим руководством. Он был награжден Почетной грамотой Иультинского райкома профсоюза и районо (1970). В свободное от работы время Т. С. Теин собирал материалы о жизни эскимосов, об истории острова. Вместе с проводником В. А. Нанауном, старейшим жителем, он побывал в различных местах острова.

В начале 1970-х гг. Т. С. Теин женился. Отсутствие собственной квартиры повлияло на решение его жены Т. Н. Теин (Ермакова) уехать к ее родителям в Воронеж. Там родилась его дочь Эля (1973 г. рожд.). Затем жена с дочерью вместе с ее родителями уехали в Молдавию жить в Кишиневе. В 1977 г. Т. С. Теин развелся с супругой, а в 1978 г. она умерла и воспитанием его дочери стали заниматься ее родители.

В 1971-1974 гг. Т. С. Теин работал в Магаданском областном краеведческом музее сначала научным сотрудником в отделе дореволюционного периода (с ноября 1971 г. по ноябрь 1972 г.), затем старшим научным сотрудником передвижного музея. Он активно изучал материалы по этнографии народов Северо-Востока Сибири. Уже тогда у него были статьи по этнографии эскимосов. За успешную работу был награжден знаком «Победитель в социалистическом соревновании 1973 г.» и получил премию Министерства культуры РСФСР. За добросовестную работу и активное участие в общественной жизни музея в честь 50 -летия образования СССР ему была объявлена благодарность.

В 1973 г. Т. С. Теин был направлен в командировку в Чукотский и Провиденский районы по маршруту Магадан - Анадырь - Нунямо - Уэлен - Лаврентия - Провидения - Сиреники - Провидения - Анадырь - Магадан. Цель командировки - сбор экспонатов по этнографии (приобретение яранги со всеми домашними принадлежностями для экспозиции музея, вельбота и других предметов), материалов в совхозах «Герой труда» (Чукотский район), «Ударник» (Провиденский район), фотосъемка лучших оленеводов, охотников, звероводов, представителей интеллигенции; сбор фолькло$\mathrm{pa}$, воспоминаний старожилов (запись на магнитофон), проведение лекций по краеведению для населения, оказание практической помощи народному музею в пос. Сиреники, работа по подготовке фотовыставки «Искусство народов Чукотки».
Т. С. Теин являлся нештатным корреспондентом газеты «Магаданский комсомолец», органа Магаданского областного комитета ВЛКСМ.

В характеристике Тасяна Сергеевича директор музея А. В. Беляева отмечала, что он добросовестно и серьезно относится к своим обязанностям, систематически выезжает в районы области и на Чукотку для обслуживания населения экспозицией передвижного музея, экскурсиями, лекциями. Также сообщалось, что он проявляет большую склонность к научной работе, занимается сбором и исследованием материалов по этнографии народов Севера, плодотворно пропагандирует материалы по краеведению в печати, на радио и телевидении.

С передвижной выставкой Т. С. Теин объездил почти всю Магаданскую область. Из каждой поездки он привозил новые этнографические экспонаты. Его первые публикации привлекли внимание историков.

В декабре 1972 г. он выступил с докладом «Традиционные праздники береговых чукчей и эскимосов (в дореволюционный и советский периоды)» на 3-й сессии Дальневосточных исторических чтений в г. Магадане. Секция археологии и этнографии рекомендовала его работу к публикации, а самого Т. С. Теина - к учебе в аспирантуре (Алехина, 1978).

На Т. С. Теина обратил внимание доктор исторических наук, заведующий лабораторией истории, археологии и этнографии СВКНИИ Н. Н. Диков. Он пригласил Тасяна Сергеевича на полевые работы на Колыму и Камчатку. Участие в экспедиции, беседы с Н. Н. Диковым, археологические находки еще более укрепили желание T. С. Теина заниматься научной работой.

T. С. Теин поступил в очную аспирантуру СВКНИИ ДВНЦ АН СССР по специальности «археология» в 1974 г. В письме директора СВКНИИ академика Н. А. Шило, направленном Председателю президиума ДВНЦ члену-корреспонденту А. П. Капице, сообщалось: «Тов. Теин Т. С. проявил глубокий интерес и незаурядные способности к изучению археологии и этнографии эскимосов и чукчей, имеет уже 11 опубликованных работ, прошел хорошую полевую археологическую практику. Он весьма перспективен как первый ученый-эскимос, и СВКНИИ ДВНЦ АН СССР заинтересован в его поступлении в очную аспирантуру под руководством заведующего лабораторией археологии, истории и этнографии д. и. н. Дикова Н. Н.». Тасяну Сергеевичу утвердили тему научной работы, связанную с изучением древних эскимосских культур Северной Чукотки.

С мая 1976 г. в связи со сложившимися семейными обстоятельствами Т. С. Теин перешел в заочную аспирантуру, был назначен на должность 
младшего научного сотрудника лаборатории. В его характеристике отмечено, что «... успеху исследований в немалой степени способствует то обстоятельство, что, будучи коренным эскимосом, он прекрасно знает эскимосский и отчасти чукотский язык. Он хорошо знает особенности жизни своего народа, фольклор, обычаи, бытовую и промысловую культуру. К истории своего народа он относится с горячим и глубоким интересом и является в этом отношении очень перспективным научным сотрудником и аспирантом». В период учебы в аспирантуре Тасян Сергеевич заболевает туберкулезом. Болезнь была длительной (два года).

В 1976 г. Северо-Чукотский отряд СВКНИИ ДВНЦ АН СССР, возглавляемый Т. С. Теином, проводил исследования в Шмидтовском районе Магаданской области (Теин, 1977a, 1979) (фото 4). На о. Врангеля отряд базировался в районе стоянки Чертов Овраг. Отсюда проводились пешие разведывательные маршруты. В целях выявления мест обитания древних охотников были обследованы берега речки Мамонтовая от среднего течения вниз до устья, а также берега лагуны Предательская. Кроме того, было осмотрено южное побережье острова от лагуны Попо-



Фото 4. Т. С. Теин на Чертовом овраге, о. Врангеля, 1976 г. Photo 4. T. S. Tein at Chyortov Ovrag, Wrangel Island, 1976 ва до лагуны Базовая, включая окрестности пос. Звездный.

На стоянке Чертов Овраг был собран подъемный материал, состоявший из 128 каменных находок. В этот полевой сезон площадь раскопа

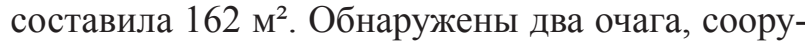
женные из вертикально поставленных плит. Интересным объектом являлась хозяйственная яма вытянутой формы, в которой оказалось множество костей морских млекопитающих и уток, а также каменные орудия.

Обилие крупных наконечников копий, черешковых метательных наконечников, ножей, скребков свидетельствует о том, что обитатели стоянки занимались преимущественно охотой на морских зверей. Большое количество утиных костей и наконечников стрел для охоты на птиц свидетельствует об активной добыче уток в летнее время. Объектом промысла были также белые медведи, нерпы и лахтаки. Каменные орудия, обнаруженные на стоянке, сходны с палеоэскимосскими комплексами Арктической Америки II тыс. до н. э.

В этом же полевом сезоне Т. С. Теин проводит исследование пунукского поселения на м. Рыркайпий ([Теин, 1987]; Диков, Теин, 1994). В культурном слое обнаружены каменные орудия (нож листовидной формы, скребки, грузило), костяные изделия (наконечник стрелы с двумя зубцами, мотыга, кирка, рукоять ножа) и другие находки.

В 1977 г. Т. С. Теином проведены раскопки $64 \mathrm{~m}^{2}$ на стоянке Чертов Овраг (Теин, 1978, 1979). В югозападном углу участка раскопа найдено много каменных орудий - ножей, скребков, обнаружены два наконечника и два тесла. По западному краю раскопа также встречались каменные орудия и найдено одно костяное изделие. На остальных квадратах были обнаружены единичные находки либо они оказались пустыми. В этот полевой сезон были обнаружены костяные изделия, относящиеся к гарпунному комплексу: обломок гарпуна (базальная часть) и колок древка из моржового клыка. Разведка к мысам Пиллар, Уэринг и Литке на вельботе из-за ледовой обстановки в этом полевом сезоне не получилась.

В 1979 г. Т. С. Теин на о. Ратманова исследовал стоянку, в культурном слое которой были обнаружены материалы оквикского, древнеберингоморского и пунукского времени (Теин, 1981a, 1985, 1994б). Интерес- 
ными находками стали амулеты: зооморфная фигурка гренландского кита из моржового клыка и фигура ворона из дерева.

В 1981 г. Т. С. Теин обследовал юго-западное побережье о. Врангеля до м. Блоссом, но ни стоянок, ни могильников найти не удалось. На Чертовом Овраге раскопано 12 м² и обнаружен еще один очаг (Теин, 1982).

В дальнейшем Т. С. Теин планировал продолжить полевые разведочные работы до м. Фомы на юго-западном побережье о. Врангеля, где, по сведениям, имелось полуподземное жилище. В 1994 г. был отправлен официальный запрос в отдел полевых исследований Института археологии РАН на продолжение раскопок палеоэскимосской стоянки Чертов Овраг Т. С. Теином. Но этим планам не суждено было сбыться.

В мае 1978 г. Т. С. Теин выступил с докладом на заседании Сектора палеолита ЛОИА* АН СССР, где было принято заключение, что доклад сделан на высоком научном уровне и его материалы исследования могут служить основой диссертации.

В конце 1970-х гг. к Тасяну Сергеевичу обратились из Ленинградского отделения Института этнографии с просьбой написать статью о шаманах сибирских эскимосов. Он занялся сбором материала и осуществил поездку на Чукотку (Поляков, 1982). В результате им была подготовлена статья, которая была опубликована в сборнике «Проблемы истории общественного сознания аборигенов Сибири», вышедшем в издатель-

* Ленинградское отделение Института археологии. стве «Наука» (Теин, 1981б). Впоследствии Т. С. Теин выявит археологические свидетельства шаманизма у древних эскимосов (Теин, 1999).

В 1980 г. Т. С. Теину присвоено ученое звание младшего научного сотрудника [Теин Т. С. Личное дело] (фото 5).

В 1985 г. Т. С. Теин изучал пунукскую стоянку на м. Якан. Предположительно на поселении выявлено 38-40 жилищ. В полуподземном жилище № 9 у входа при расчистке были собраны каменные и костяные изделия, среди них гравировальный инструмент из клыка моржа. Особенно важным для определения возраста и культурной принадлежности являлся костяной типично пунукский наконечник поворотного гарпуна (Теин, 1990). В этом году коллектив Северо-Чукотской историко-археологической группы (начальник отряда Т. С. Теин) был награжден дипломом как призер конкурса полевых отрядов.

В следующем, 1986 г. Т. С. Теин исследовал на м. Биллингса жилище древнеберингоморского времени. На мысе обнаружено древнее поселение, которое состояло из 16 жилищ. Одно из них, № 1 , огромных размеров $(40 \times 20$ м), являлось, скорее всего, общественной землянкой, где в древности проводились зрелищные мероприятия. У входа другой землянки, № 2 (размером $13 \times 9$ м), был заложен шурф. Находки представлены костяными и каменными изделиями. Наиболее интересными являются наконечник поворотного гарпуна, защитный наручник лука из кости и шлифованные орудия из камня (Там же).

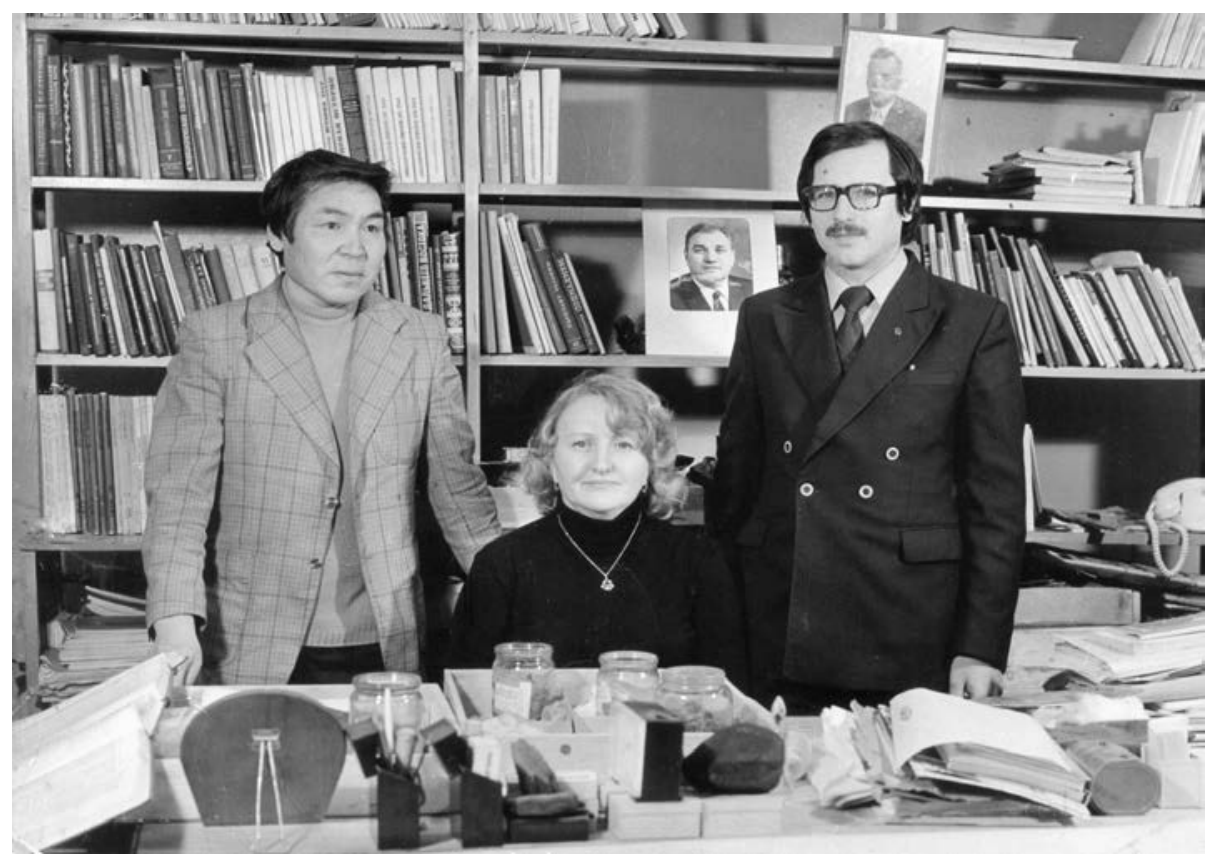

Фото 5. Т. С. Теин в камеральном помещении СВКНИИ с сотрудниками лаборатории А. А. Воропаевой и А. И. Лебединцевым

Photo 5. T. S. Tein in the office room of the NEISRI with laboratory staff A. A. Voropayeva and A. I. Lebedintsev 
В этом же полевом сезоне Т. С. Теин планировал разведывательные раскопки в с. Наукан, где еще С. И. Руденко в 1945 г. собрал подъемный археологический материал, но их не удалось провести. Для осуществления этой поездки необходимо было использовать самолет до Лаврентия, вертолет до Уэлена и вельбот до Наукана.

К концу 1980-х гг. он провел семь очень успешных полевых сезона и в труднейших условиях Северной Чукотки собрал значительный археологический материал по теме исследований. О своих задачах в науке он писал, что ясно осознает свой общественно-научный долг - написать по археологическим материалам древнюю историю своего народа.

На материалах раскопок жилища древнеберингоморского периода с м. Рыркайпий им опубликовано исследование о применении китового уса в хозяйственной жизни древних морских зверобоев Северной Чукотки (Теин, 1980).

Совместно с А. В. Беляевой Т. С. Теин опубликовали коллекцию археологических находок пунукского времени из жилища № 1 Уэленской стоянки. Среди находок присутствуют орудия охоты (наконечник поворотного гарпуна из клыка моржа, вкладышевое копьецо из сланца и др.), орудия труда (сланцевый нож, каменные скребки для обработки шкур, грузило из клыка моржа, тесло, наконечник пешни, пластины-накладки с отверстиями, мотыга для выкапывания съедобных корней растений, подвеска с орнаментом и др.) (Беляева, Теин, 1982).

В 1983 г. в Магаданском книжном издательстве выходит книга Т. С. Теина о раскопках на о. Врангеля (Теин, 1983). Книга основана на дневниковых записях, сделанных в период нескольких археологических экспедиций на остров. Дневниковые выдержки перемежаются с экскурсами в историю освоения и изучения острова и описанием современного быта его жителей. Книга написана ярким и сочным языком, легко читается (Гунько, 1985). Недавно она была переиздана на английском языке на Аляске в США (Three Works..., 2018).

На о. Врангеля Т. С. Теин собрал интересные сведения и материалы об иностранной экспансии на остров, о первых поселенцах и их быте. Многие предметы и вещи из собранного материала затем экспонировались в Магаданском областном краеведческом музее.

В конце 1980-х гг. велись переговоры по организации советско-американского сотрудничества в области изучения и сохранения природного и культурного наследия в районе Берингова пролива. Т. С. Теин входил в группу подготовки предложений к этому проекту как эксперт по археологии, этнографии, истории и культуре коренного населения. Участники встречи по проблеме
«Берингийского наследия» посетили в сентябре 1989 г. пос. Провидения, на корабле отправились в район пролива Сенявина, затем побывали на побережье бухты Лаврентия и в районе пос. Уэлен и вернулись опять в пос. Провидения. Везде на этих местах были проведены полевые наблюдения. После этого в течение 5 дней советско-американская группа совершила облет Чукотского полуострова на вертолетах лепестковыми маршрутами в целях обследования состояния памятников природы и истории. Дальнейшие работы участников проходили на Аляске, куда все они отправились 17 сентября 1989 г. (фото 6).

Т. С. Теин участвовал в 7-й конференции по исследованиям инуитов «Взгляд в будущее» на Аляске в 1990 г. (г. Фэрбенкс), где выступил с докладом об изучении древних стоянок на Северной Чукотке (Tein, 1990).

В 1991 г. Т. С. Теин защитил кандидатскую диссертацию «Древнеэскимосская культура Северной Чукотки, включая острова Врангеля и Ратманова» ([Теин, 1987]; Теин, 1991). Научным руководителем соискателя был доктор исторических наук, член-корреспондент АН СССР Н. Н. Диков. В качестве оппонентов выступали известные ученые - археолог, доктор исторических наук 3. А. Абрамова и этнограф, кандидат исторических наук Г. Н. Грачева. В заключении специализированного диссертационного совета сообщалось, что Т. С. Теин, обобщив свои новые материалы с ранее известными, дал целостную картину развития эскимосской культуры Северной Чукотки на основных этапах ее развития, начиная от палеоэскимосского и практически до этнографической современности. Особенно детально он реконструировал хозяйство и культуру палеоэскимосского и древнеберингоморского этапов. Важные выводы были сделаны Т. С. Теином о древних жилищах и бытовом инвентаре эскимосов, о связи их морского промысла с бытовым ремеслом, в частности с применением китового уса, о высоком развитии их искусства, с большей, чем предполагалось ранее, древности у них шаманизма, о древних истоках эскимосских традиций (в охоте на китов, моржей и на белого медведя), в строительстве жилищ, в общественном строе, в религиозных верованиях и обрядах, ритуальных праздниках.

Н. Н. Диков в отзыве на диссертацию Т. С. Теина отмечал: «Отличное знание и понимание живой этнографии эскимосов, их обычаев и образа жизни ... позволяет ему глубоко проникать в сущность предметов древней культуры, правильно понимать их назначение и видеть за ними живых людей».

В 1986 г. Т. С. Теин был назначен на должность научного сотрудника. 


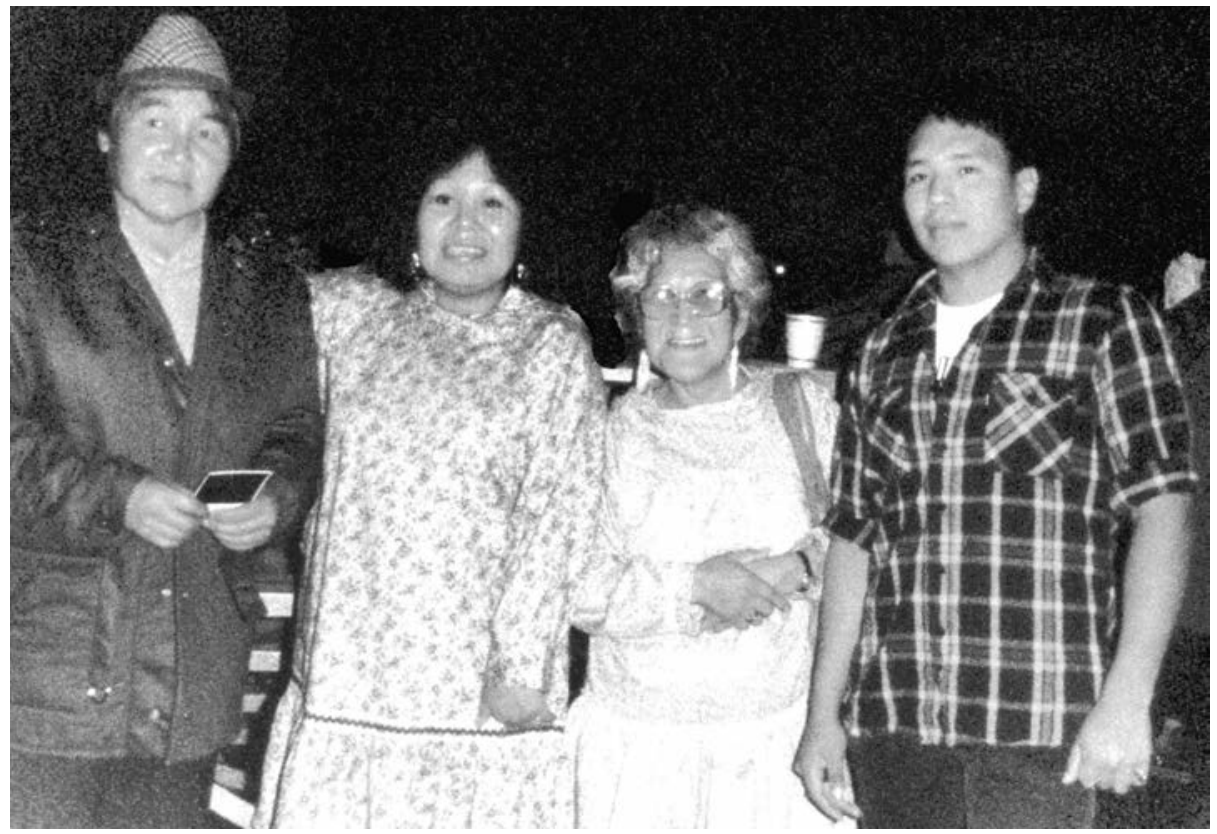

Фото 6. Т. С. Теин (первый слева) с эскимосами Аляски на конференции старейшин региона Берингова пролива, сентябрь 1989 г. 1989

Photo 6. T. S. Tein (on the left) with Alaska Eskimos at the Bering Straits Region Elders Conference, September

Областьнаучных интересов Т. С. Теина-археология древних эскимосов, религия и шаманизм азиатских эскимосов, но он активно занимался общественной работой, сотрудничал с учреждениями культуры, писал статьи в газеты.

Т. С. Теин на общественных началах принимал участие как консультант в руководстве чукотскоэскимосским ансамблем «Энер», оказывал методическую помощь Управлению культуры, давал консультации Отделу по народностям Севера Магаданского облисполкома, проводил большую работу в Обществе охраны памятников истории и культуры, публиковался в местной печати.

Где бы Т. С. Теин не находился, он первым делом заходил в школу (встречался с учителями из коренных народов Чукотки, выступал перед старшеклассниками), читал лекции в сельских клубах (Иванов, 1982). Навещал он также свои родные места, где проживали науканские эскимосы (фото 7).

В апреле 1982 г. по приглашению Чукотского окружного отдела культуры Т. С. Теин выступил с лекциями в Анадыре по темам: «Эскимосские праздники», «Методика проведения эскимосских обрядов на новой социалистической основе», «Шаманы сибирских эскимосов» для участников окружного семинара по национальному фольклору. Кроме того, у него были выступления по окружному радиовещанию: «Два мира - две судьбы» и «Наши полевые исследования». Отдел культуры вручил Благодарность Т. С. Теину за большую творческую помощь слушателям семинара.
Дирекция Государственного чукотско-эскимосского ансамбля «Эргырон» выразила благодарность Т. С. Теину за очень квалифицированную помощь в области эскимосского искусства во время его гастролей в г. Магадане в октябре 1983 г.

В 1987 г. в г. Анадыре проходил Второй окружной праздник национального искусства Чукотки, в подготовке которого принимал участие T. С. Теин. Окружным отделом культуры ему вручена Благодарность за большую творческую помощь в проведении окружного семинара по национальным праздникам и обрядам, а также высказано пожелание о более тесном сотрудничестве в дальнейшей работе по развитию национального художественного творчества.

Еще в 1970-х гг. Т. С. Теин описал традиционные праздники науканских эскимосов: праздник кита «полъа» и первый спуск байдары на воду (Теин, 1975, 1977б). Эти праздники были тесно связаны с бытом и хозяйством морских охотников. Источником для написания этих статей стали рассказы старожилов-эскимосов.

В 1988 г. Т. С. Теин принимал участие в организации советско-американского национального праздника в пос. Провидения. Он написал сценарии национальных праздников азиатских эскимосов (Теин, 1984, 1992), предложив методику проведения праздников в эскимосских селениях. Обе эти книги были переизданы в США (Three Works..., 2018).

T. С. Теин подготовил методические рекомендации по проведению эскимосских обрядов на 


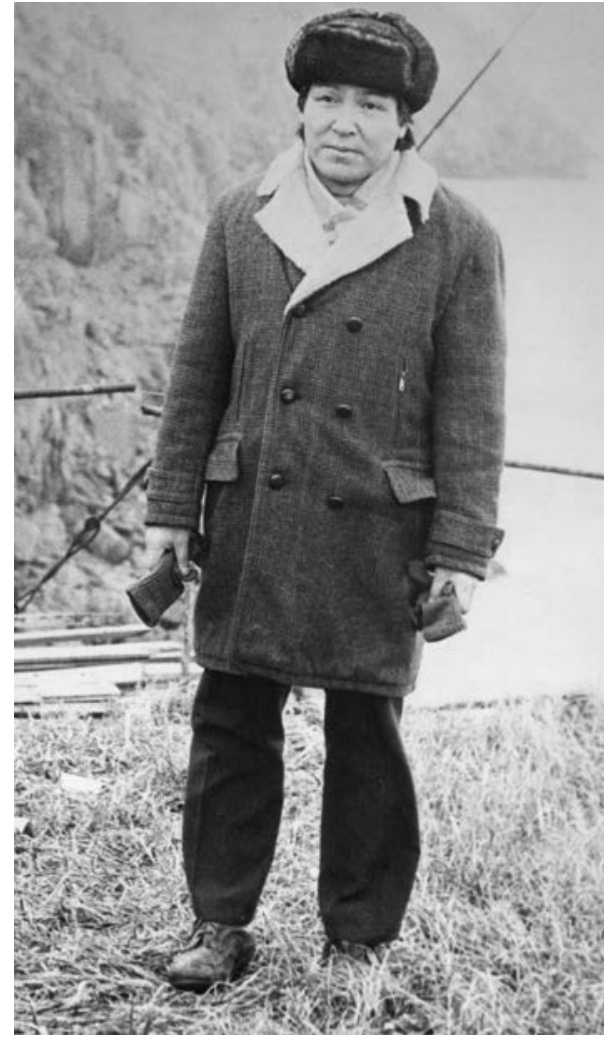

Фото 7. Т. С. Теин на месте бывшего эскимосского селения Наукан, 1980-е гг.

Photo 7. T. S. Tein on the site of the former Eskimo village of Naukan, 1980s

новой современной основе. В сценарий праздника кита он включил, кроме производственных действий (буксировка добытого кита с ритуалом встречи в море и на берегу, разделка туши животного, костер, чаепитие), фольклорную часть с песнями и танцами зверобоев, кукольным представлением, обрядовыми действиями и спортивными соревнованиями (Огрызко, 1990. С. 100). В работе о праздниках эскимосов Т. С. Теин предстает перед читателями не только как исследователь исторического прошлого своего народа, но и как сценарист и пропагандист современных обрядов и обычаев (Гунько, 1985).

В книге «И было так ...» Т. С. Теин подробно описывает ритуалы эскимосов, обращая особое внимание на их воспитательное значение: «... Каждый ритуал имел свое магическое предназначение, и, кроме того, он воспитывал трудолюбие, уважение к труду старшего поколения, любовь к природе, воспитывал чувства и мысли о том, что человек и природа - единое иеелое, где каждый зависит от другого, и поэтому необходимо очень бережно относиться к природе» (Теин, 1992. С. 42).

В планах Магаданского книжного издательства предполагалось издание других книг Т. С. Теина: монографии «Азиатские эскимосы начи- ная с древнейших времен и до XVII века» и сборника рассказов для детей «Приключения нерпенка Пилъыка», а также были поданы заявки еще на две книги: «Религиозные верования и обряды, шаманизм азиатских эскимосов», «По следам древних эскимосов» (Иванов, 1982; Еременко, 1992).

В 1990 г. Т. С. Теин передал в Магаданское книжное издательство рукопись поэтического сборника на русском языке. Ему пообещали, что вставят его книгу в план, но она так и не была издана. Книжное издательство стало выпускать коммерческую литературу, обои, а рукопись, вероятно, затерялась. Дубликат рукописи он больше никуда не приносил (Огрызко, 2013).

К Т. С. Теину обращались американские ученые с просьбой издать в США его работу «Шаманы сибирских эскимосов» (Еременко, 1992). Статья вышла в журнале "Arctic Anthropology» (Tein, 1993a). Кроме того, на английском языке у него опубликованы еще две статьи, посвященные традициям, ритуалам и верованиям эскимосов (Tein, 1993b, 1995).

В 1993 г. Т. С. Теин участвовал в конкурсе на лучшую научную работу. Его «Очерки культуры азиатских эскимосов» заняли III место в этом конкурсе.

В 1994 г. в сборнике, подготовленном Магаданским отделением Всероссийского общества охраны памятников истории и культуры, опубликованы статьи Т. С. Теина, посвященные эскимосским поселениям Яндогай и Наукан (Теин, 1994а, 1994в). Наукан как историко-этнографический памятник представлен в ранее вышедшей статье Т. С. Теина (1977в).

По программе научно-исследовательских работ лаборатории археологии и истории на 1996 1998 гг. Т. С. Теину была утверждена тема «Религия и шаманизм азиатских эскимосов».

О Т. С. Теине много писали в газетах как об ученом (Денисов, 1977; Алехина, 1978; Иванов, 1982; Алексеева, 1984; Маламуд, 1984; Гунько, 1985; Еременко, 1992; и др.). Он привлекал внимание как писатель и краевед (Огрызко, 1990, 1999, 2007, 2008, 2013; Гобзев, 2008; Трапезников, 2008). О его научной деятельности написано в статье американского археолога Э. Дж. Диксона (2004) и в энциклопедии «Encyclopedia of the Arctic» (Slobodin, 2004).

Им опубликовано 27 научных работ, в том числе книга «Тайна Чертова оврага» (1983), есть публикации за рубежом. Известен он и своими популярными статьями в местных изданиях.

В 1998 г. Тасян Сергеевич уволился из СВКНИИ по собственному желанию.

С 1998 по 2005 г. Т. С. Теин находился в Магаданском областном психоневрологическом диспансере на 23-м км основной трассы под Ма- 
гаданом. Умер он 7 сентября 2005 г. Похоронен на Магаданском городском кладбище, 14-й км основной трассы, г. Магадан.

Тасян Сергеевич Теин благодаря собственным личностным качествам и внешним обстоятельствам жизни стремился узнать как можно больше об истории и обычаях своих предков и донести это до последующих поколений. В определенный момент он осознал свой общественно-научный долг - написать по археологическим материалам древнюю историю своего народа. Полученное им высшее образование, учеба в аспирантуре и защита кандидатской диссертации дали ему большую теоретическую базу, что он непрерывно совмещал с практикой. Процесс занятия археологией и этнографией у Т. С. Теина был многосторонним, он переживал за свое дело, был активным популяризатором полученных знаний, участвуя в проведении национальных праздников, восстановлении обрядов и обычаев эскимосов, стремился увлечь этим читателей своих публикаций. Он сумел сплавить собственные впечатления и опыт жизни «внутри народа» с объективным, научным взглядом на древнюю и современную историю эскимосов. Из этого симбиоза родились публикации, имеющие непреходящую научную ценность в сфере археологии и этнографии. Важное значение имеют исследования Т. С. Теина древнего прошлого эскимосов.

Им охарактеризованы основные этапы развития древней эскимосской культуры Северной Чукотки, дана реконструкция хозяйства и культуры, исследованы общественный строй, религиозные верования и обряды эскимосов. Археологические исследования Т. С. Теина на о. Врангеля внесли значительный вклад в изучение древнейшей истории эскимосов Северной Чукотки. Были получены достаточно представительные и интересные материалы с поселения древних охотников на морского зверя. Он исследовал религию и шаманизм азиатских эскимосов, выполнил детальные описания эскимосских сезонных праздников.

\section{ЛИТЕРАТУРА}

Алексеева T. Призвание // Советская Чукотка. 1984. 30 сент

Алехина А. Судьба Тасяна Теина // Советская Чукотка. 1978. 29 окт.

Беляева А. В., Теин Т. С. Археологическая коллекция из села Уэлен // Краевед. записки. Магадан : Кн. изд-во, 1982. Вып. 12. С. 124-129.

Гобзев И. Цветы во льдах // Эскимосская литература: материалы и исследования. Москва : Литературная Россия, 2008. С. 248-251.

Гунько С. Кто жил на острове Врангеля? // Дальний Восток. 1985. № 2. С. 156-157.

Денисов Е. Ошибки старого шамана // Магаданская правда. 1977. 10 июня.

Диков Н. Н., Теин Т. С. Древнеэскимосские поселения на м. Рыркайпий // Памятники, памятные места истории и культуры Северо-Востока России (Ма- гаданская область и Чукотка). Магадан : Кн. изд-во, 1994. С. 34-37.

Диксон Э. Джеймс. Пионеры Берингийской археологии // Северные просторы. 2004. № 1-2. С. 145-146.

Еременко Ж. Ученость самой высокой пробы // Магаданская правда. 1992. 14 мая.

Иванов В. Тема работы - жизнь эскимосов // Coветская Чукотка. 1982. 26 сент.

Маламуд B. Праздники Чукотки // Магаданский комсомолец. 1984. 2 окт.

Огрызко В. Звуки языка родного. Магадан : Кн. изд-во, 1990. 125 с.

Огрызко В. Писатели и литераторы малочисленных народов Севера и Дальнего Востока : Биобиблиограф. справочник. Ч. 2. Москва : Концерн «Литературная Россия», 1999. 548 с.

Огрызко В. Теин Тасян // Североведы России : материалы к биографическому словарю. Москва : Литературная Россия, 2007. С. 465-466.

Огрызко В. Азиатские эскимосы: писатели и литераторы: библиографический справочник // Эскимосская литература: материалы и исследования. Москва : Литературная Россия, 2008. С. 384-509.

Огрызко В. Пропавший археолог: Тасян Теин // Мир Севера. 2013. № 1. С. 55-59.

Поляков А. Как искали шамана // Известия. 1982. 8 февраля.

Теин Т. С. Эскимосский праздник кита «полъа» (на примере п. Наукан) // Краевед. записки. Магадан : Кн. изд-во, 1975. Вып. 10. С. 88-94.

Теин T. С. Исследования в Чертовом овраге на о. Врангеля // Археологические открытия 1976 года. Москва : Наука, 1977а. С. 246-247.

Теин T. С. Первый спуск байдары на воду (из жизни науканских эскимосов) // Краевед. записки. Магадан : Кн. изд-во, 1977б. Вып. 11. С. 115-120.

Теин Т. С. Эскимосское селение Наукан - историкоэтнографический памятник // Памятники истории и культуры Магаданской области. Советский период. Вып. 2. Магадан : Кн. изд-во, 1977в. С. 25-29.

Теин T. С. Изучение палеоэскимосской культуры на о-ве Врангеля // Археологические открытия 1977 года. Москва : Наука, 1978. С. 278.

Теин T. С. Археологические исследования на о. Врангеля // Новые археологические памятники Севера Дальнего Востока (по данным СВАКАЭ). Магадан : СВКНИИ ДВНЦ АН СССР, 1979. С. 53-63.

Теин T. С. Применение китового уса в хозяйственной жизни морских зверобоев Чукотки // Новейшие данные по археологии Севера Дальнего Востока (материалы Северо-Восточно-Азиатской комплексной археологической экспедиции). Магадан : СВКНИИ ДВНЦ АН СССР, 1980. С. 79-88.

Теин Т. С. Полевые исследования на о-ве Ратманова // Археологические открытия 1980 года. Москва : Наука, 1981а. С. 216.

Теин T. С. Шаманы сибирских эскимосов // Проблемы истории общественного сознания аборигенов Сибири. Ленинград : Наука, 1981б. С. 218-232.

Теин T. С. Раскопки на о-ве Врангеля // Краевед. записки. Магадан : Кн. изд-во, 1982. Вып. 12. С. 124 129.

Теин T. C. Тайна Чертова оврага. Магадан : Кн. изд-во, $1983.94 \mathrm{c.}$

Теин T. С. Праздники эскимосов : Описание популярных в древности праздников эскимосов и ме- 
тодика их проведения. Магадан : Кн. изд-во, 1984. $32 \mathrm{c.}$

Теин Т. С. Культовые амулеты с о. Ратманова // Новое в археологии Севера Дальнего Востока (материалы СВАКАЭ). Магадан : СВКНИИ ДВНЦ АН СССР, 1985. C. 109-115.

Теин Т. С. Древние стоянки на мысах Биллингса и Якан (Шмидтовский район) // Древние памятники Севера Дальнего Востока (новые материалы и исследования СВАКАЭ). Магадан : СВКНИИ ДВО АН СССР, 1990. C. 112-122.

Теин Т. С. Древнеэскимосская культура Северной Чукотки, включая острова Врангеля и Ратманова : автореф. дис. ... канд. ист. наук. Ленинград, 1991. 18 с.

Теин T. С. И было так ... Очерки традиционной культуры азиатских эскимосов. Магадан : Магадан. обл. центр народного творчества и досуга, 1992. 65 с.

Теин T. C. Древнее поселение эскимосов - Яндогай // Памятники, памятные места истории и культуры Северо-Востока России (Магаданская область и Чукотка). Магадан : Кн. изд-во, 1994а. С. 42-44.

Теин T. С. Древнеэскимосские памятники на о-ве Ратманова // Памятники, памятные места истории и культуры Северо-Востока России (Магаданская область и Чукотка). Магадан : Кн. изд-во, 1994б. С. 44- 47.

Теин T. С. Эскимосское селение Наукан - историкоэтнографический памятник // Памятники, памятные места истории и культуры Северо-Востока России (Магаданская область и Чукотка). Магадан : Кн. издво, 1994в. С. 60-63.

Теин T. С. Археологические свидетельства шаманизма у древних эскимосов // История, археоло- гия и этнография Северо-Востока России. Магадан : СВКНИИ ДВО РАН, 1999. С. 96-99.

Tрапезников A. A. Остров и Материк Теина // Эскимосская литература: материалы и исследования. Москва : Литературная Россия, 2008. С. 224-230.

Slobodin S. B. Tein Tasyan // Encyclopedia of the Arctic. Vol. 3. New York : Routledge Press, 2004. P. 2011-2013.

Tein T. S. New data on the development of the early Eskimo culture in North Chukotka / $7^{\text {th }}$ Inuit Studies Conference "Looking to Future". Fairbanks, 1990. P. 31-32.

Tein T. S. Shamans of the Siberian Eskimo // Arctic Anthropology. 1993a. Vol. 30, No. 1. P. 35-47.

Tein T. S. Traditions, ritual and beliefs // Anthropology and Archaeology of Eurasia. 1993b. Vol. 31, No. 3. P. 82-86.

Tein T. S. Traditions, ritual and beliefs of the Asiatic Eskimos // Culture Incarnate. Native Anthropology from Russia. New York; London, 1995. P. 209-214.

Three Works by Tasyan Sergeevich Tein. Anchorage : National Park Service, 2018. 156 p.

\section{АРХИВНЫЕ МАТЕРИАЛЫ}

Теин Т. С. Древнеэскимосская культура Северной Чукотки, включая острова Врангеля и Ратманова : промежут. отчет. Архив СВКНИИ, № 1600. 1987. $179 \mathrm{c}$.

Теин Т. С. Личное дело // Научный архив СевероВосточного комплексного научно-исследовательского института (СВКНИИ ДВО РАН).

Поступила в редакиию 22.06.2021 2.

Поступила после доработки 21.07.2021 2.

\section{TASYAN S. TEIN : LIFE AND RESEARCH}

\section{A. I. Lebedintsev}

North-East Interdisciplinary Scientific Research Institute n. a. N. A. Shilo, FEB RAS, Magadan

The article presents the biographical data and the main research results of Tasyan S. Tein, archaeologist, researcher of the Laboratory of History, Archeology, and Ethnography, NEISRI. He described the main stages in the development of the ancient Eskimo culture of Northern Chukotka, reconstructed the economy and culture, researched the social structure, religious beliefs, and rituals of Eskimos. Excavations on Wrangel Island made a significant contribution to the study of the Paleo-Eskimo period. T. S. Tein obtained representative and valuable materials from the most ancient settlement of sea mammal hunters. He researched the religion and shamanism of the Asiatic Eskimos, and completed detailed descriptions of the Eskimo seasonal festivals.

Keywords: history of archaeological research, ancient sites, Northern Chukotka, T. S. Tein.

\section{REFERENCES}

Alekseyeva, T., 1984. Calling, Sovetskaya Chukotka. September, 30 [In Russian].

Alyokhina, A., 1978. The Fate of Tasyan Tein, Sovetskaya Chukotka. October, 29 [In Russian].

Belyayeva, A. V., Tein, T. S., 1982. Archaeological Collection from Uelen Village, Kraevedcheskiye Zapiski. Magadan. 12, 124-129 [In Russian].

Denisov, E., 1977. The Errors of an Old Shaman, Magadanskaya Pravda. June, 10 [In Russian].
Dikov, N. N., Tein, T. S., 1994. Ancient Eskimo Settlements on Cape Ryrkaipiy, Sites and Memorable Places of History and Culture of Northeast Russia (Magadan Oblast and Chukotka). Magadan. 34-37 [In Russian].

Dikson, E. James, 2004. Pioneers of Beringian Archaeology, Severniye Prostory. 1-2, 145-146 [In Russian].

Eremenko, Zh., 1992. Scholarship of the Highest Kind, Magadanskaya Pravda. May 14 [In Russian]. 
Gobzev, I., 2008. Flowers in the Ice, Eskimo Literature Materials and Research. Moscow, Literaturnaya Rossiya. 248-251 [In Russian].

Gunko, S., 1985. Who Lived on Wrangel Island? Dalniy Vostok. 2, 156-157 [In Russian].

Ivanov, V., 1982. Work Topic: Eskimo Life, Sovetskaya Chukotka. September 26 [In Russian].

Malamud, V., 1984. Chukotka Festivals, Magadanskiy Komsomolets. October 2 [In Russian].

Ogryzko, V., 1990. Sounds of the Mother Tongue. Magadan [In Russian].

Ogryzko, V., 1999. Writers and Literati of the Native Peoples of the North and Far East: A Bibliographic Reference Book, Pt. 2. Moscow, Literaturnaya Rossiya [In Russian].

Ogryzko, V., 2007. Tein Tasyan, Researches of Russia's North: Materials for a Biographical Dictionary. Moscow. 465-466 [In Russian].

Ogryzko, V., 2008. Asian Eskimos: Writers and Literati : Bibliographic Reference Book, Eskimo Literature: Materials and Research. Moscow, Literaturnaya Rossiya. 384-509 [In Russian].

Ogryzko, V., 2013. The Missing Archeologist: Tasyan Tein, Mir Severa. 1, 55-59 [In Russian].

Polyakov, A., 1982. How They Looked for a Shaman, Izvestiya. February 8 [In Russian].

Slobodin, S. B., 2004. Tein Tasyan, Encyclopedia of the Arctic. New York, Routledge Press. 3, 2011-2013.

Tein, T. S., 1975. Eskimo Whale Festival "Pol'a" (Exemplified by the Settlement of Naukan), Kraevedcheskiye Zapiski. Magadan. 10, 88-94 [In Russian].

Tein, T. S., 1977. Investigations at Chyortov Ovrag on Wrangel Island, Archeologicheskiye Otkrytiya 1976. Moscow, Nauka. 246-247 [In Russian].

Tein, T. S., 1977. The First Launching of the Baidara (from the Life of the Naukan Eskimos), Kraevedcheskiye Zapiski. Magadan. 11, 115-120 [In Russian].

Tein, T. S., 1977. The Eskimo Village of Naukan: A Historical-Ethnographic Site, Sites of History and Culture of Magadan Oblast. Soviet Period. Magadan. Iss. 2, 2529 [In Russian].

Tein, T. S., 1978. Study of the Paleo-Eskimo Culture on Wrangel Island, Archeologicheskiye Otkrytiya 1977. Moscow, Nauka [In Russian].

Tein, T. S., 1979. Archaeological Investigations on Wrangel Island, New Archaeological Sites in the North of the Far East (According to the North-East Asian Complex Archaeological Expedition). Magadan, SVKNII DVNC AN USSR. 53-63 [In Russian].

Tein, T. S., 1980. The Use of Baleen in the Economic Life of Sea Mammal Hunters in Chukotka, The Most Recent Data on the Archaeology of the Northern Far East (Materials from the Northeast Asian Interdisciplinary Expedition). Magadan, SVKNII DVNC AN USSR. 79-88 [In Russian].

Tein, T. S., 1981. Field Research on Ratmanov Island, Archeologicheskiye Otkrytiya 1980. Moscow, Nauka [In Russian].

Tein, T. S., 1981. Siberian Eskimo Shamans, Problems of History of Social Consciousness in Siberia's Natives. Leningrad, Nauka. 218-232 [In Russian].

Tein, T. S., 1982. Excavations on Wrangel Island, Kraevedcheskiye Zapiski. Magadan. 12, 115-120 [In Russian].
Tein, T. S., 1983. The Mystery of the Devil's Gorge. Magadan [In Russian].

Tein, T. S., 1984. Eskimo Festival: A Description of Popular Ancient Festivals and the Methodology of Conducting Them. Magadan [In Russian].

Tein, T. S., 1990. New Data on the Development of the Early Eskimo Culture in North Chukotka, $7^{\text {th }}$ Inuit Studies Conference "Looking to the Future", Fairbanks. 19-24 August 1990. 31-32.

Tein, T. S., 1990. Cult Amulets from Ratmanov Island, News in the Archaeology of the Northern Far-East (Materials of the SVAKAE). Magadan, SVKNII DVO AN USSR. 109-115 [In Russian].

Tein, T. S., 1990. Early Sites on Cape Billings and Cape Yakan (Shmidt District), Early Sites in the Northern Far East (New Materials and Research of the SVAKAE). Magadan, SVKNII DVO AN USSR. 112-122 [In Russian].

Tein, T. S., 1991. Ancient Eskimo Culture of Northern Chukotka, Including Wrangel and Ratmanov Islands: Avtoref. Dis. ... Kandidata Ist. Nauk. Leningrad [In Russian].

Tein, T. S., 1992. It Was Like This ...: Essays on the Traditional Culture of the Asiatic Eskimos. Magadan [In Russian].

Tein, T. S., 1993. Shamans of the Siberian Eskimo, Arctic Anthropology. 30 (1), 35-47.

Tein, T. S., 1993. Traditions, Rituals, and Beliefs, Anthropology and Archaeology of Eurasia. 31 (3), 8286.

Tein, T. S., 1994. The Ancient Eskimo Settlement of Yandogay, Sites and Memorable Places of History and Culture of Northeast Russia (Magadan Oblast and Chukotka). Magadan. 42-44 [In Russian].

Tein, T. S., 1994. Ancient Eskimo Sites on Ratmanov Island, Sites and Memorable Places of History and Culture of Northeast Russia (Magadan Oblast and Chukotka). Magadan. 44-47 [In Russian].

Tein, T. S., 1994. The Eskimo Vilage of Naukan: A Historical-Ethnographic Site, Sites and Memorable Places of History and Culture of Northeast Russia (Magadan Oblast and Chukotka). Magadan. 60-63 [In Russian].

Tein, T. S., 1995. Traditions, Rituals, and Beliefs of the Asiatic Eskimos, Culture Incarnate. Native Anthropology from Russia. New York, London. 209-214.

Tein, T. S., 1999. Archaeological Evidence of Shamanism in Ancient Eskimos, History, Archaeology, and Ethnography of Northeast Russia. Magadan, SVKNII DVO RAN. 96-99 [In Russian].

Three Works by Tasyan Sergeevich Tein, 2018. Anchorage.

Trapeznikov, A. A., 2008. Tein Island and Continent, Eskimo Literature: Materials and Research. Moscow, Literaturnaya Rossiya [In Russian].

\section{ARCHIVAL MATERIALS}

Tein, T. S., 1987. Ancient Eskimo Culture of Northern Chukotka, Including Wrangel and Ratmanov Islands, Interim Report, SVKNII Archives, 1600 [In Russian].

Tein, T. S. Personal File, Scientific Archives of the North-Eastern Interdisciplinary Scientific Research Institute (NEISRI FEB RAS) [In Russian]. 